\title{
DESECHOS, CARENCIAS Y COMPENSACIONES: \\ UNA REFLEXIÓN DESDE LA ANTROPOLOGÍA FILOSÓFICA
}

\author{
Patricia Cecilia Bernal Maz* \\ doi:10.11144/Javeriana.uph31-62.dcca
}

\begin{abstract}
RESUMEN
La reflexión antropológica ha definido al ser humano como un ser que escapa de sus propias deficiencias gracias a que es capaz de existir únicamente a través del despliegue de múltiples estrategias de compensación. El concepto de compensación tiene un lugar central en la antropología filosófica, recoge diferentes perspectivas que permiten contemplar diferentes formas de relaciones humanas y de comunicación con el mundo. Esta reflexión se estructura en cuatro momentos: 1. El olvido mediante el recuerdo. 2. Espacios de compensación, de conservación y de recuerdo. 3. Lo nuevo es, a la vez, lo viejo y anacrónico. 4. Las descargas. El texto busca dilucidar nuevos retos que debe afrontar la antropología filosófica para pensar la autocomprensión del hombre contemporáneo en su búsqueda por superar sus propias deficiencias a través de la compensación que le proporciona la misma vida.
\end{abstract}

Palabras clave: Antropología filosófica; autocomprensión; comunicación; olvido; compensación

\footnotetext{
* Pontificia Universidad Javeriana, Bogotá, Colombia.

ReCIBIDO: 18.09.13 ACEPTADO: 27.11.13

DISPONIBLE EN LÍNEA: 30.06 .14

Para citar este artículo: Bernal Maz, P.C. (2014). Desechos, carencias y compensaciones: Una reflexión desde la antropología filosófica. Universitas Philosophica, 31(62), 195-219. ISSN 0120-5323; ISSN en línea 2346-2426; doi:10.11144/Javeriana.uph31-62.dcca
} 


\title{
GARBAGE, DEPRIVATIONS AND COMPENSATIONS: A REFLECTION FROM PHILOSOPHICAL ANTHROPOLOGY
}

\author{
Patricia Cecilia Bernal Maz
}

\begin{abstract}
Anthropology has defined man as a creature who seeks refuge from his natural deficiencies and can only exist by using multiple compensation strategies. The idea of compensation plays a key role in philosophical anthropology, implies different perspectives involved in the various ways human beings relate to each other and communicate with the external world. This reflection is devised in four main moments: 1. Forgetting by remembering 2. Compensation, preservation and remembrance 3 . What is new is both old and anachronistic 4 . Release. This text aims at elucidating new challenges for philosophical anthropology in the explanation of how contemporary man seeks to overcome his/her own deficiencies through compensations life itself offers.
\end{abstract}

Key words: philosophical anthropology; self-understanding; communication; oblivion; compensation 


\section{El olvido mediante el recuerdo}

UNA BREVE REFLEXIÓN ACERCA DEL OLVIDO Y EL RECUERDO sirve de marco para abordar más adelante la compensación como estrategia de descarga. La antropología filosófica se acerca así a una de sus cuestiones fundamentales, a saber: el ser humano y su autocomprensión en el mundo contemporáneo. Es la época de los desechos, las carencias y el olvido y, al mismo tiempo, es la época del derroche de compensaciones. Todo el mundo es desmemoriado, afirma Harald Weinrich. A todo el mundo le ha pasado haberse olvidado aquí de esto, allá de aquello y haber olvidado por completo alguna cosa trabajosamente aprendida de memoria. Las percepciones del olvido propio $\mathrm{y}$ ajeno forman parte, desde la juventud, de las experiencias elementales de toda persona y son una de las plagas de la senectud (Cfr. Weinrich, 1999: 15). Es más, se observa cómo el olvido está, de hecho, directamente conectado con la memoria. Desde la perspectiva de Weinrich, cuando se recurre a la memoria a manera de metáfora, las propias del olvido ocupan en este paisaje -preferentemente, los páramos y los terrenos arenosos- el lugar de la representación. Esta idea puede verse expresada con toda claridad en Una oda al olvido de Federico el Grande:

Cuando estudio, esperando

haber grabado en mi alma

cuanto de importancia han

producido la paz y la guerra,

busco en vano en mi memoria,

Nada sé ya de la historia

que sabía hace un instante;

como un surco volandero

que se traza por la arena

se lo lleva el menor viento,

Igual haces perecer,

canalla y hombre de bien,

el mérito y el poder,

nada sirven contra ti.

¿Qué vana es nuestra grandeza!

Olvidado está ya Eugenio

acaba de fenecer,

Y del olvido no le salvan

Panteón ni funerales, ni sus famosas batallas (Citado por: Weinrich, 1999: 150). 
Entonces, da lo mismo escribir algo en la arena que en el viento. Desde esta perspectiva se puede también enterrar algo voluntariamente, de tal modo que la hierba crezca sobre ello, quedando por fuera del mundo. Igualmente, si se piensa la memoria como un almacén o un depósito, es más cercano el olvido cuanto más se desciende a esos sótanos. Pero, quizá el olvido, dicho de una forma elemental, no es más que un agujero en la memoria, en el que algo cae o desaparece. El olvido, oculto o yacente en las profundidades es, pues, por su naturaleza, oscuro. Para Schiller, el olvido tenebroso es donde la noche gana toda su dimensión terrorífica (Cfr. Weinrich, 1999: 21-22).

Con más detenimiento, para atender al problema del olvido, es importante hacer referencia a las imágenes y comparaciones que proceden del mito desde las tempranos griegos. Entre ellos, Lete es una deidad femenina que forma pareja con su opuesta Mnemosine, la diosa de la memoria y madre de las musas. Según la genealogía y la teogonía, Lete procede de la estirpe de la noche. No obstante, el abolengo representa un escaso papel en la recepción de este mito, porque Leteo es ante todo el nombre de un río que traza los límites del infierno y ofrece el olvido a las almas de los muertos (Cfr. Weinrich, 1999: 24). En esta imagen, el olvido se sumerge por completo en esas aguas. Su suave fluir disuelve los duros contornos del recuerdo de la realidad pues, de alguna manera, todos ellos son liquidados, licuados, en sus aguas. Algunos autores de la antigüedad coinciden en que las almas bebieron de las aguas del Leteo y ello les ocasionó el olvido de su existencia anterior. Ahora deben hacerse libres y renacer en un nuevo cuerpo. En este contexto, la muerte sería el más poderoso agente del olvido (Cfr. Weinrich, 1999: 55). Pero, la muerte no es omnipotente; desde siempre, contra su olvido, los seres humanos han levantado las murallas del recuerdo, de tal modo que las huellas que permiten seguir la memoria de los muertos pasan por ser los signos más seguros de la existencia de una cultura humana. Empero, cuando esta posibilidad del recuerdo también se ha perdido, se disipa con ello, definitivamente, el rostro humano de la muerte. Por esta razón, la muerte gana terreno cuando ni siquiera se recuerda a los muertos. El poeta Elie Wiesel alude con dolor a su propia vivencia del sufrimiento en el campo:

Jamás olvidaré esa noche, la primera noche en el campo, que ha hecho de mi vida una larga noche siete veces maldita. Jamás olvidaré el humo. Jamás olvidaré los pequeños rostros de los niños, cuyos cuerpos se convirtieron en volutas ante mis ojos en un azul silencioso. Jamás olvidaré esas llamas 
que consumieron para siempre mi fe. Jamás olvidaré ese silencio nocturno, que me privó por toda la eternidad del deseo de vivir. Jamás olvidaré esos instantes que asesinaron mi Dios y mi alma, y convirtieron mis sueños en polvo del desierto. Jamás olvidaré todo eso, aunque estuviera condenado a vivir tanto tiempo como Dios mismo. Jamás. (Citado por: Weinrich, 1999: 303)

El fragmento destaca que los rituales de culto a los muertos sirven para asegurar el recuerdo de los que han partido; igualmente, la figura de los monolitos construidos por el hombre primitivo advierte que no se debe olvidar a sus muertos. No ha sido en vano que filólogos homéricos y farmacólogos hayan empleado mucho esfuerzo en averiguar con exactitud qué clase de planta puede haber sido la que produjo ese fármaco del olvido. Se ha pensado en un determinado nenúfar o loto del que se sabe que tenía notable importancia en el culto egipcio a los muertos y que se consumía en forma de flor.

Sin embargo, y de acuerdo con Weinrich, hoy no es posible establecer de manera inequívoca el papel de esa planta entre el recuerdo de los muertos y su olvido. De igual modo, se observa que de los versos de la epopeya no se desprende con claridad si la droga causaba olvido permanente o solo pasajero. Lo único seguro es que el fruto del loto, además de poseer un sabor dulce, brinda un dulce olvido. Es más, dicho sabor se deja traducir en el olvido de los amantes, como se advierte claramente en la más bella de las historias de amor de Casanova, cuando narra su encuentro con Henriette y forma dentro de sus recuerdos una pequeña novela de amor. Henriette, así se llama una joven aventurera francesa que Casanova conoce por azar en una hostería y viaja por Italia disfrazada de varón, en compañía de un capitán húngaro de sesenta años. Pasados tres meses, a su vuelta de Parma, Casanova encuentra una carta escrita de puño y letra por Henriette, cuyo texto exacto recoge en su autobiografía. En el párrafo de la misiva concerniente al olvido lee:

Soy yo, mi único amigo, la que tenía que abandonarte. No hagas más grande tu dolor pensando en el mío. Imaginemos que hemos tenido un sueño agradable, y no nos quejemos de nuestro destino, porque nunca un sueño tan agradable ha durado tanto. Ensalcémonos, pues, por haber sabido hacernos plenamente felices durante tres meses seguidos; apenas hay mortales que pueden decir una cosa así. Ojalá que no nos olvidemos nunca el uno al otro, y a menudo recordemos nuestro amor con el pensamiento para reavivarlo en nuestras almas, donde a pesar de nuestra separación nos alegraremos mucho más vivamente de él. Por eso, no hagas 
averiguaciones sobre mí, y si el azar quisiera facilitarte saber quién soy, compórtate como si no lo supieras. Permíteme decirte, mi querido amigo, que he puesto en orden mis asuntos y seré por el resto de mi vida tan feliz como pueda serlo sin ti. No sé quién eres; pero sé que nadie en el mundo te conoce mejor que yo. En toda mi vida futura ya no tendré amantes, pero deseo que tú no tengas la misma idea. Quisiera que siguieras amando, e incluso que encuentres otra Henriette, Adieu (Weinrich, 1999: 146-147).

Resulta paradójico o, por lo menos, curioso, cómo la manera más efectiva de poder olvidar es, precisamente, olvidar mediante el recuerdo. La sabiduría de nuestros antepasados fija en la memoria privada de los muertos un marco ritual en el culto público que, en la sucesión repetida de las conmemoraciones, refuerza la memoria más allá de la tumba y al mismo tiempo la limita mediante su habitualidad social (Cfr. Weinrich, 1999: 55). Pero, cuando los poetas con el poder de su pluma hacen suyo el recuerdo de los muertos, el olvido ya no puede practicar su repetido juego con la memoria de los hombres. De hecho, Dante levantó en torno a la memoria de los muertos, siempre amenazada por el olvido, un receptáculo de noticias. Asimismo, para escapar a todas las tentaciones del olvido, Dante promete al final de la Vida nueva que durante el resto de su vida se alzará un monumento literario al perenne recuerdo de Beatrice. Aquella mujer a la que, por morir tan joven, Dante no pudo expresarle en vida toda la veneración y todo el amor que había sentido por ella.

Mas, ¿qué decir del olvido de la propia identidad, del yo olvidado? El italiano Luigi Pirandello no solo jugó a ello en sus novelas, relatos y obras de teatro, sino que también lo puso en escena y, al mismo tiempo, gracias a la ironía, lo desenmascaró como ficción en este doble juego. El protagonista de la novela El difunto Matías Pascal, que le da nombre, cuenta su historia en primera persona pero, desde el más allá, porque para el mundo él ya está muerto y difunto. Sin embargo, él mismo, sigue viviendo con otra identidad como un hombre insignificante llamado Adriano Meis, que ha hecho su fortuna en la ruleta en Montecarlo y ahora puede llevar una vida confortable con los intereses de sus ganancias. El cambio de identidad no ha sido planeado. Matías Pascal malvivía como bibliotecario en una ciudad italiana, junto a su mujer, Romilda, siempre despeinada, y una suegra gruñona que le amargaba la vida día tras día. Además, soportaba deudas agobiantes. Al final de una de las muchas peleas domésticas, simplemente abandona a su familia sin despedirse, llevando algunas liras en su bolsillo. El dinero le alcanza justo para un viaje a Montecarlo y para una apuesta arriesgada 
en el tablero. La suerte le es propicia y abandona el casino convertido en un hombre rico. Ahora puede volver con su familia y reemprender su vida conyugal después de trece días de ausencia. Cuando está sentado en el tren, su mirada cae sobre una noticia de prensa titulada "suicidio". Un muerto, se lee allí, ha sido identificado por su propia esposa como Matías Pascal, quien había desaparecido desde hace días. Es libre. Así que comienza una nueva vida y necesita un nuevo nombre. Si bien ha perdido su identidad, aún no lo ha perdido todo; la pérdida deviene ahora en la posibilidad de tener una vida mejor de la que tenía antes al lado de su esposa.

Claro está, existen otras historias que relatan el olvido con tintes poéticos. Por ejemplo, al Califa Harun al-Raschid no todo le va como debería en lo que al amor respecta. Entre las esclavas de su harén hace mucho que ama a una belleza a la que, sin embargo, últimamente, ha postergado un poco. ¿La ha olvidado acaso? Han discutido, y la esclava a la que aflige el enfado, busca consuelo en el vino prohibido por el profeta. Una noche, el Califa se encuentra con la esclava dando tumbos, borracha, por el palacio. $\mathrm{Y}$ es eso lo que precisamente inflama de nuevo su pasión y tiende los brazos hacia ella para abrazarla. Pero la esclava esquiva su deseo y le consuela con promesas para el próximo día, cuando esté mejor preparada para su llegada. Al día siguiente, el Califa le anuncia por un criado que irá a visitarla en sus aposentos, ella se niega a recibirle y le envía el siguiente mensaje: "El día claro borra las palabras de la noche".

Del relato se desprende una cierta dimensión compensatoria propia del olvido y que permite restablecer el orden del mundo. ¿Cómo se ha de entender el rechazo de la esclava? ¿Por qué olvida de día la promesa hecha la noche anterior? ¿Quizá porque el Califa ha olvidado antes a la amada? De hecho, el Califa juega el grotesco papel de un olvidador olvidado. Pero ¿puede permitirse el Emir de los creyentes semejante desaire? ¿Habrá jugado la esclava un juego demasiado peligroso? Se verá entonces cómo sigue la historia. Para sorpresa del lector, el drama del olvido del harén de Bagdad se resuelve de forma pacífico-poética. El Califa ha quedado impresionado por la sabiduría de la frase de la esclava: "el día claro borra las palabras de la noche". Teniendo esta frase en mente, ordena a los tres poetas de su corte el encargo de que cada uno de ellos componga al instante un poema cuyo verso final rece: "el día claro borra las palabras de la noche". Así ocurre. De los tres poemas que estos le presentan distingue con premios los versos de los poetas Al-Raqasi y Abu Mus'ab. En cambio, este poema de Abu Nuwás, se va de vacío: 
Largo fue el amor, más estuvimos lejos.

Reñimos; más de nada sirvió la riña.

La encontré embriagada, de noche, en palacio;

más era casta incluso en la embriaguez.

De sus hombros la túnica derribó el jugueteo;

también cayeron prestas las otras ropas.

De la rama colgaban delicadas manzanas,

el viento sacudía las caderas.

Dije: ¡dale a tu amado fiel promesa!

Y ella le dijo: Mañana se cumplirá.

De mañana fui y dije: ¿Tu palabra? Y ella dijo:

El día claro borra las palabras de la noche (Weinrich, 1999: 166).

Es evidente, entonces, que el olvido tiene múltiples matices y tonalidades grises tejidas en la densa incertidumbre de lo cotidiano. Es el llamado mundo de las sombras y de las tinieblas. Lo que es olvidado se desecha y se considera como algo inservible o, definitivamente, se lo envía al baúl de los recuerdos, de las cosas perdidas o, más bien, de los pendientes que el hombre va coleccionando en el transcurrir de su vida.

No cabe duda, hasta aquí, de que el olvido es propio del hombre y de su experiencia de vida. Sumado a ello y, siguiendo en este punto a Marquard, se advierte la existencia de otra forma del olvido representada actualmente en el mundo de la basura y el mundo del desecho, la cual da paso a la conformación de una sociedad del culto por lo novedoso y lo renovable (Cfr. Marquard, 2001: 51). La finitud factual quizá impulsa a los seres humanos a desarrollar una cultura museística para poder conservar su pasado y su cultura.

\section{Espacios de compensación, espacios de conservación y del recuerdo}

LA CRECIENTE VELOCIDAD DE INNOVACIÓN INCREMENTA, también de manera acelerada, la masa de cosas pasadas de moda. Arrojar las cosas viejas a la basura se convierte ciertamente en un procedimiento recurrente dentro de las culturas modernas; de esta manera, se expanden y se propagan los vertederos y los depósitos de desechos que convierten al mundo en una central de basura ecológica y tecnológica, fruto del progreso y del avance del mundo contemporáneo. Para comprender este hecho es indispensable incursionar en la perspectiva antropológica de Marquard y en su concepto del desechar, entendido más como el mundo de la conservación y del recuerdo, y como un 
espacio de compensación que crea la necesidad de una cultura conservadora y museística. Asimismo, el autor observa cómo el mundo del desechar se encuentra en medio de las ciudades invadidas por la producción de objetos inútiles, en las que emerge la necesidad de crear espacios para guardar los recuerdos, tan ineludibles como los espacios dónde habitar.

En el mundo moderno, lo desechado deviene una categoría interesante y venerada. En otras palabras, se percibe cómo los artistas plásticos copian el entorno de la naturaleza y plasman en sus lienzos las naturalezas muertas como recuerdos de una época. Los arquitectos que, de acuerdo con los problemas medioambientales no tendrán más espacio donde crear y re-crear sus ideas, van guardando en edificios de épocas anteriores los recuerdos del presente; $\mathrm{y}$, con el paso del tiempo, habrá más cosas olvidadas, desechadas y recordadas; cosas que solo son para ser guardadas y salvadas de su inevitable desaparición. A la par, surgen múltiples espacios donde las tradiciones, las costumbres, los trajes típicos de las diferentes culturas del mundo, los oficios, los aborígenes, los indígenas, las especies naturales que se extinguen, los seres humanos que transforman sus cuerpos, encuentran ahora refugio: los museos, los centros de conservación, los lugares hechos para el recuerdo.

En este afán desmedido de recuerdo, al mismo tiempo que se venera estéticamente lo desechado por el hombre, se da entrada a los excluidos, a los marginados, a los que sufren el progreso y perecen por él. Cuanto más rápido se convierte el presente en pasado gracias a las innovaciones, más se fortalece el interés por lo pasado únicamente para ser guardado en un depósito. Todo lo presente se consume a la velocidad con la que la información circula permitiendo que todo se encuentre disponible para el consumo (Cfr. Marquard, 2001: 59); y es así como las particularidades de cada una de nuestras culturas, de cada uno de los individuos, son neutralizadas por la disponibilidad consumista.

Ante este panorama de uniformización global y circunvolución, lo particular se convierte en la compensación de ese universal. Desde la perspectiva de Sloterdijk, medio milenio después de los viajes de Colón se presenta la tierra circunvolucionada, descubierta, representada, ocupada y utilizada como un cuerpo entretejido en una tupida red de movimientos circulatorios y rutinas telecomunicativas (Cfr. Sloterdijk, 2004: 848) que hacen de lo lejano algo enigmáticamente más cercano. Hoy nada está lo suficientemente lejos como para pasar desapercibido a la mirada calculadora 
y con ansias de dominación. A manera de ejemplo, desde el punto de vista aeronáutico, la tierra se ha reducido a un trayecto en avión fácilmente realizable si se dispone del dinero necesario para romper las distancias que nos separan de los sitios más remotos. Tras el hecho de que la tierra está circunvolucionada y que los pueblos y culturas más alejados han accedido a ella bajo la presión de la mediación, ya no hay lugar a retroceder en el tiempo (Cfr. Sloterdijk, 2004: 848).

Aunque los pueblos diseminados hayan vivido hasta ahora en sus endocontinentes como estrellas separadas escondidas del exterior, y en sus clausuras lingüísticas y territoriales, casi todos se ven obligados a admitir y a reconocer, ahora por fuerza de la modernidad unificadora de las diferencias, que se vive en uno y el mismo planeta, en la estrella de los desencubiertos que envuelve a todo lo existente. Hoy todo está abiertamente descubierto en su disponibilidad esencial pero, dado que la globalización terrestre es un mero factum, que ha aparecido tardíamente y bajo circunstancias históricas particulares, esta no se puede interpretar como manifestación de una verdad eterna ni como una necesidad ineludible. Por ende, sería totalmente absurdo ver en ella la expresión natural del axioma biológico de que todos los seres humanos sobre la tierra constituyen una única especie. Tampoco ello demuestra, según Sloterdijk, la idea metafísica de que todos los seres humanos participan en definitiva de uno y el mismo tesoro de verdades irrevisables.

A la luz de estas problemáticas, el ser humano se ve impelido a enfrentar con afán la puesta en escena de la evidencia de la materialización y artificialización del mundo contemporáneo, cuyas debilidades busca compensar con el despliegue de acciones que le permitan superar sus propias carencias. Así, se hizo patente que, en la medida en que el mensaje encubierto $\mathrm{y}$, sin embargo, omnipresente de la facilitación de la vida se materializaba en los ánimos de las generaciones venideras, la interpretación del mundo a la vista del prejuicio de la carencia se iba situando en una posición poco plausible (Cfr. Sloterdijk, 2006: 529). El espíritu conservador de la miseria y negador del bienestar ha invertido, sobre todo desde los años setenta, grandes esfuerzos en la desvalorización de la riqueza occidental, y ha demostrado la insostenibilidad de los métodos empleados hasta ahora para su adquisición. De ahí que la trascendencia que tuviera el debate internacional sobre los límites del crecimiento tradujera el pesimismo económico al lenguaje de 
la ecología, atrayendo a una juventud alternativa. Asimismo, y siguiendo en este punto a Sloterdijk, se reconoce que el esfuerzo más ambicioso del conservadurismo indigente frente al giro hacia una civilización del bienestar consistió, sin embargo, en situar a mayor profundidad los fundamentos conceptuales de una ontología de la carencia.

Lo anterior solo pudo suceder cuando se hizo de la carencia una especie de esencia negativa y se la desligó de los datos económicos para situarla en el interior mismo de la esencia humana. No obstante, todavía se pretende juzgar la existencia humana bajo el punto de vista de su determinación como carencia, puesto que esta no puede ser tratada como una privación fáctica, casual y reversible de bienes materiales y simbólicos de una gran mayoría de personas reales; lo que importa ha de presentarse ahora como una necesidad apriórica constitucional o biocultural de los humanos. Evidentemente, no es un ser de carencias originadas por la misma evolución el que le preocupa a la antropología filosófica; antes bien, se trata del ser de lujo que es el propio ser humano, del aligeramiento de la incertidumbre de la vida en sociedad que ha sido dictaminado por la miseria y la penuria (Cfr. Sloterdijk, 2006: 538). En esta forma, lo único que le interesa al ser humano es eliminar todo rastro del pasado buscando siempre la novedad en su presente. Empero, cabe resaltar que las disoluciones de la ligereza autoconsciente solo fueron posibles en el horizonte de una sociedad que, gracias a la acumulación de bienestar, ciencia y técnica, se encontraba a punto de salir del ámbito de la historia.

\section{Lo nuevo es a la vez, lo viejo y anacrónico}

DE LAS CONSIDERACIONES ANTERIORES NO SE HACE DIFÍCIL INFERIR que la búsqueda esencial del ser humano actual se concentra en un mundo artificial y simulado que lo aleja de su ser espiritual. En realidad, en este mundo contemporáneo de cambios acelerados a velocidades indescriptibles, los humanos se han convertido, paradójicamente, en seres lentos, sin que ninguno de los dos se pueda suprimir ni evitar. La aceleración y la creciente velocidad provocan que las cosas pasen de moda, y este paso mismo de la moda se hace también a una velocidad progresiva. De ahí que, cuanto más rápido lo nuevo pasa a ser viejo, lo viejo pasa a ser nuevo y, así, para Marquard, en la moderna carrera de la historia, cuanto más aumenta la velocidad, más tranquilamente debería uno dejarse adelantar y esperar hasta que el curso del mundo, regresando por atrás, le alcance de nuevo (Cfr. Marquard, 2001: 78). 
Así las cosas, lo nuevo, convocado por la técnica, necesita echar mano de antiguas destrezas desarrolladas por los seres humanos por miles de años. Ya no se leen ni se escriben cartas; el lápiz, como técnica escritural por excelencia, deviene un objeto de museo que cuenta sus propias historias. En este siglo de grandes avances, el lápiz ha sido reemplazado por un ambiente digital en el que se escribe y, tal vez, se lee de forma inmediata; asimismo, el teléfono ha resuelto todos los problemas comunicativos de nuestro presente, siendo cada vez más interactivo y multifuncional. En otras palabras, "el estudiante de literatura y filosofía tiende a preocuparse por el contenido del libro y a ignorar su forma" (McLuhan, 1985: 99). Esta omisión es peculiar en los que conocen y emplean el alfabeto fonético, puesto que las personas recrean en su lectura el contenido que representa el habla en el código visual. La imprenta con su uniformidad, su capacidad repetitiva y su extensión sin límites, dio nueva vida y fama a cualquier cosa que exista. Hoy esto se logra por otros medios de comunicación más potentes y ágiles. Ya no se estudian a fondo los artículos, se fotocopian fragmentos de ellos. Ya no se leen los libros, se ve televisión o se lee digitalmente; los datos se encuentran en la red; sobran los diarios. Es así como los modos de expresión literaria y de comunicación se han transformado y se han individualizado, segmentado y mecanizado cada vez más; la visión de la literatura, de la lectura y la escritura será tribal y colectiva y la expresión será privada y comercializable (Cfr. McLuhan, 1985: 316).

Resulta fácil establecer el hecho de que los mismos medios, con la producción en serie, ayudaron a configurar un mundo de abundancia para el consumidor y sirvieron, igualmente, para apoyar los más altos niveles de la producción artística sobre bases más seguras. A medida que el hombre experimenta la nueva era electrónica y orgánica con indicaciones cada vez más definidas de sus perfiles principales, la era mecánica precedente se va haciendo cada vez más inteligible. Hoy, cuando el montaje tipográfico retrocede ante los nuevos sistemas de información, sincronizados, inmediatos y simultáneos, los milagros de la producción en masa se hacen completamente inteligibles. Pero las novedades de la automatización, al ir creando y conformando comunidades sin trabajo, envuelven a la humanidad actual en nuevas problemáticas e incertidumbres, a las que se responde con el mismo arsenal tecnológico y conceptual que generó las inseguridades, de modo tal que se renueva la cadena. 
Ciertamente, los medios de comunicación y de información se valen de la tecnología para aligerar el peso de la cotidianidad de los seres humanos, buscando una supuesta descarga que no puede ser permanente. En otras palabras, los medios ahorran el tiempo de buscar la información al obtenerla de forma inmediata y simultánea; es más, toda esta información se puede almacenar sin que exista un límite para ello. Pero esta posibilidad se vuelve rápidamente una condena; ya no se cuenta con el suficiente tiempo para atender la demanda de una información que crece de modo exponencial. La urna en la que hoy se navega se expande en la virtualidad; la información que se guarda en las páginas es innumerable y, en definitiva, desborda los conceptos tradicionales del espacio físico, determinado por sus propias medidas.

Lo que en Nietzsche solo era un problema específico de los historiadores y de los filólogos - la creciente carga de recuerdos de la historia- se convierte en el siglo XXI en un problema general de la sociedad: el incesante crecimiento de datos que se ofrecen como información que debe ser conocida, se almacena en miles de bits y, finalmente, se los desecha en la virtualidad de la red (Cfr. Weinrich, 1999: 339). Desde este punto de vista, la sociedad de la información es un sistema que integra todas las estructuras sociales y las formas de vida en una red de características globales. El sueño se ha convertido en una sola e interminable pesadilla.

¿Qué tipo de información es vital para el hombre y cuál otra no lo es? ¿Cuál sería la información a desechar? Se ha de advertir que la cantidad de lo impreso crece más aprisa diariamente, y al cabo de un breve tiempo, desborda todos los espacios y sistemas de ordenación, bien sea atiborrando anaqueles o una memoria virtual. En este escenario, ninguna sociedad o ningún individuo, sin perder su identidad, puede digerir tantas innovaciones en tan poco tiempo como las que hoy se nos ofrecen como información (Cfr. Weinrich, 1999: 351).

El relato de Heinrich Böll, publicado en el año 1957 con el título de $E l$ desechador, sirve de ilustración:

La historia se desarrolla en Colonia. Allí hay una honorable compañía de seguros llamada Ubia, que da trabajo a 350 empleados. Entre ellos, uno -el narrador en primera persona de la historia-tiene una nueva tarea especial que cumplir. Este empleado desempeña sus servicios antes de las horas 
regulares de oficina y, después, una vez más sin llamar la atención, por la tarde, durante una hora, en cada ocasión poco después de llegar el correo. $\mathrm{Su}$ tarea consiste en clasificar el correo recibido y tirar sin abrirlos todos los envíos superfluos antes de que lleguen a los oficinistas de la empresa. Este personaje tan importante es el desechador.

Este hombre está bien cualificado para esta importante tarea, que tiene que hacer todos los días a manos llenas, casi como un nadador - ¿en la corriente del Leteo? - es un caballero educado, en torno a la treintena, de buenos modales. En su vida civil lleva un traje cruzado gris y en el trabajo un guardapolvo gris. También en lo demás se comporta en más de un sentido como el Gris del relato de Chamisso, con el que le une también la discreción del estricto anonimato. Este caballero gris no solo ha escogido, sino inventado esta profesión, y la define exactamente con respecto a su función siempre negadora: esta actividad sirve exclusivamente a la aniquilación.

Sin embargo, su vocación de desechador no fue reconocible desde la primera infancia. Primero fue un voraz coleccionista que acopiaba incansablemente toda la información que le caía entre manos: folletos de viajes, ofertas de vino del Rin, catálogos de arte de todo tipo, etcétera, etcétera, hasta que un día, a los diecisiete años, llegó la gran crisis y conversión, en la que de un día para otro el celoso coleccionista se convirtió en el apasionado tirador y desechador. Una teoría general de la economía cimentó pronto la praxis cotidiana del oficio de desechador, de manera que pudo pensar en enseñar el arte y la crítica de la razón desechadora en una escuela de desechadores propia (Weinrich, 1999: 339-340).

El relato permite descubrir un comportamiento en nada extravagante, antes bien, muy cotidiano. Lo que no sirve se tira, se elimina, se desecha; igual destino tiene la información que se almacena en la memoria por un tiempo y luego se la arroja al bote de la basura virtual. ¡Cuántas cosas inútiles se encuentran dentro de sobres perfectamente franqueados y en otras muy respetables cubiertas! Hay que recurrir a aparatos con mejores y mayores capacidades de memoria para que almacenen y a la vez desechen lo inservible. Este es precisamente el problema que debe ser atendido hoy en el mundo moderno de la producción, del desecho y del reciclaje (Cfr. Weinrich, 1999: 341).

A pesar de todo, el ser humano no se detiene a pensar en lo que sucede a su alrededor; para ello no tiene tiempo. Está al frente de cambios extraños a escala global y no se percata de la inminencia con que estos acontecen. El mundo como se conoce hoy ya no será el mismo en unas décadas, y el 
hombre no se ha percatado aún de qué es lo que precisamente ha cambiado. Antes bien, durante los últimos treinta años, el mundo se ha sobrepoblado con las consecuencias que se observan y la ecología del mundo se sigue transformando a costa del progreso. La economía del planeta está por encima del ecosistema y descansa sobre la contaminación. El mundo se enferma desde su interior, las micro-bacterias abundan en los peces en el fondo de los océanos y cuando se los consume se convierten en peligro para la vida de los seres humanos. En definitiva, el hombre contemporáneo se encuentra solo.

Desde un punto de vista blumenberguiano, se puede decir que los seres humanos no soportan la proximidad de Dios; por esta razón, inventaron en la Edad Media el primer intento de superación de la gnosis. Después, en la modernidad, se emprendió un segundo intento para protegerse del absolutismo teológico, esto es, poder tomar distancia de un Dios demasiado omnipotente mediante la invención de una cultura de la autoconservación y autoafirmación. En otras palabras, los males del mundo ya no aparecen como características metafísicas de la cualidad del principio cósmico o de la justicia punitiva, sino como rasgos de la facticidad misma de la realidad (Cfr. Blumenberg, 2008: 135). Esto se dio en la modernidad pues en la Edad Media no parecía que se hubiera tomado en consideración al ser humano ya que se contaba con un sistema de poder que era realmente indiferente frente a la autoconservación de todo lo existente; en la modernidad, se descubrió que el mal radicaba en todo aquello que se oponía a su propia voluntad de vida.

Siguiendo a Blumenberg, se puede señalar que la Edad Media tocaba a su fin cuando dentro de su sistema intelectual ya no era posible seguir sosteniendo la credibilidad del carácter providencial de la idea de creación, circunstancia que hacía cargar sobre el ser humano todo el peso de su autoafirmación. Por esta razón, la autoafirmación no significa hoy la pura conservación, en el plano biológico y económico, del servivo que es el hombre mediante los instrumentos disponibles a su naturaleza (Cfr. Blumenberg, 2008: 136). Significa, más bien, todo un programa existencial, donde el ser humano inserta su propia vida en una situación histórica concreta y en la que él se hace su propio esbozo sobre cómo acometer esta tarea y aprovechar sus posibilidades que se le abren al interior de su realidad circundante. En efecto, ha tenido lugar un cambio fundamental en la comprensión del mundo, en las esperanzas y valoraciones e interpretaciones que esta conlleva, un cambio que no consiste simplemente en una suma de hechos de la experiencia, sino que abarca todo un compendio de anticipaciones que determinan, a su vez, el 
horizonte de posibles experiencias y su interpretación que contiene los datos de la relación del hombre con su propio mundo.

Por otra parte, además de los componentes biológicos de la autoconservación propios del ser humano que, como ser vivo ha aparecido en el escenario del mundo deficientemente equipado y adaptado, el refuerzo y la ayuda de instrumentos y procedimientos técnicos fueron necesarios para que el hombre se asegurara la satisfacción de sus necesidades más vitales, importantes y elementales. Este instrumental de la autoconservación permaneció constante durante largo tiempo y con un abanico mínimo de variantes. Por ello los seres humanos, no soportando el dolor del mundo, intentan olvidarlo volviendo la mirada hacia el cosmos inmenso y magnífico, y emplean la teoría inventada por los griegos e, igualmente, la tragedia de estos. Luego, tras el desencantamiento del mundo copernicano, el cosmos desaparece en un eterno desierto sin nada que descubrir, sin nada de qué sorprenderse y del cual los seres humanos tienen que descargarse mediante una afirmación de la tierra como un espacio libre.

Es a través del mito, siguiendo una vez más a Blumenberg, como se va transformando la realidad en una pluralidad de historias y sus horrores, en juegos, en una división arcaica y mítica de poderes; en esta forma, los seres humanos se descargan de la realidad absoluta mediante su transformación distanciadora en una realidad legible que impone la tarea de leerla y releerla, quizá tal como es ofrecida hoy por los científicos que decodifican el código genético.

Asimismo, para descargarse de la mortalidad, del peso de su finitud y del mundo exterior, los seres humanos construyen sus cavernas del mismo modo como los animales buscan su refugio puesto que se encuentran expuestos al mundo. Una vez más, según Blumenberg, dos fenómenos culturales expresan la necesidad biológica y psíquica de la regresión: la tumba y la ciudad; siendo la ciudad la repetición de la caverna con otros medios (Cfr. Blumenberg, 2003: 69). Desde esta perspectiva, la ciudad le quita realidad a todo aquello de lo que ella depende, y de esta manera permite que se olvide el rasgo parasitario de su propia existencia. La forma de vida urbana favorece un mayor grado de abstracción en la captación de la realidad. Hay que trabajar, según Blumenberg, con representaciones simbólicas de géneros y valores mercantiles. Por eso en la ciudad el concepto representa todo aquello que él no hace propiamente presente; no obstante, lo que hay que mantener disponible es realidad todavía no presente. 
Aquello que en la caverna del mito platónico supone la desventaja ontológica de las sombras, el distanciamiento que su condición dúplice conlleva respecto de aquello que precisamente representan, es la única ventaja de la antropogénesis, esto es, la de hacerse presente internamente lo que está fuera. Justo por ello la ciudad no necesita de la magia; al contrario es el lugar donde esta pierde sus poderes; en ella, las realidades se calculan, las ilusiones no se toleran y no se aceptan a cuenta de presuntas ganancias. A la postre, esas ilusiones se refugian en las instituciones, en las que se desarrolla la cultura y la reflexión con la que los hombres mantienen la distancia con la realidad absoluta cuya inmediatez se convierte en un asunto peligroso (Cfr. Marquard, 2001: 115). En otras palabras, la cultura es el trabajo de esa distancia que al mismo tiempo suaviza la unicidad mediante la pluralidad, mediante la descarga de ese absoluto. La descarga es comprendida aquí no solo como un exitoso vocablo de la antropología de Gehlen, sino también por referencia a un concepto jurídico del derecho penal y privado por el que se exonera, se exime, a presidentes, a sospechosos, a personas, a dioses (Cfr. Marquard, 1986: 29).

\section{Las descargas}

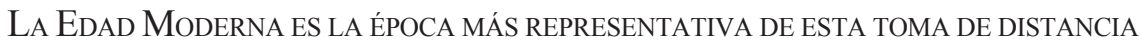
y la primera época en la que la impotencia y el sufrimiento ya no son algo normal para los seres humanos que, simplemente, los aceptan como tales. En otras palabras, la miseria parece estar bajo control, el dolor es evitable, la enfermedad es derrotable, lo malvado es eliminable y, finalmente, la finitud del ser humano puede llegar a ser superable si, obviamente, se cuenta con un régimen de vida adecuado para ello.

De lo anterior se puede inferir que la humanidad necesita cada vez menos a Dios. Esta idea de que en todo caso los males presentes en el mundo pueden ser compensados suficientemente por los bienes, o son bonificados por ellos, es un motivo claramente teodiceico propio de la Edad Moderna (Cfr. Marquard, 1986: 42). Para Marquard, la idea de compensación pudo convertirse en un motivo teodiceico porque de acuerdo con la teodicea de Leibniz el nexo antiguo de la némesis, según el cual las malas acciones son compensadas, es decir, castigadas mediante males, fue invertido con el nexo moderno de la mitigación. De hecho, los defectos son ahora compensados y reparados mediante bondades. Esta forma moderna de compensación, según el autor, inspira desde el siglo XVIII y hasta el siglo XIX esmerados balances filosófico-compensatorios que procuran demostrar que en el mundo no 
predominan los males sobre los bienes sino que, por el contario, predominan los últimos sobre los primeros creando un equilibrio entre ambos.

A manera de ejemplo, son oportunos algunos fragmentos de Cándido, de Voltaire:

Es realmente admirable, dijo Cándido, pero por lo pronto hay que curarlo. - ¿Y cómo?, dijo Pangloss; no tengo un centavo, mi amigo; y en toda la superficie del globo no es posible hacerse sangrar ni ponerse una lavativa sin pagar, o sin que alguien pague por uno.

Estas últimas palabras hicieron que Cándido se decidiera; fue a botarse a los pies de su caritativo anabaptista Santiago, y le pintó un cuadro tan conmovedor del estado en el que se encontraba su amigo, que el buen hombre no dudó en acoger al doctor Pangloss, y se encargó de su curación. Durante el tratamiento, Pangloss no perdió más que un ojo y una oreja. Como escribía bien y manejaba la aritmética a la perfección, el anabaptista Santiago lo hizo tenedor de sus libros. Al cabo de dos meses tuvo que viajar a Lisboa por cuestión de negocios, y se embarcó con sus dos filósofos. Pangloss le explicó cómo todo sucedía de la mejor manera posible, pero Santiago no era de ese parecer. Es necesario, decía, que los hombres hayan corrompido un poco la naturaleza, puesto que no nacieron lobos y acabaron siéndolo. Dios no les dio cañones de veinticuatro ni bayonetas, y ellos fabricaron bayonetas y cañones para destruirse. Podría traer a cuento el caso de las bancarrotas, y de la justicia que se apropia de los bienes de los que quiebran para defraudar a los acreedores. Todo eso es indispensable, replicaba el doctor tuerto; las desgracias particulares conducen al bien general, de modo que entre más desgracias particulares haya, mejor irá todo (Voltaire, 1996: 24-25).

Este pasaje muestra la voluntad de servicio hacia el otro que refleja Cándido al solicitar ayuda para su amigo enfermo que sufre una calamidad personal. Las desgracias particulares que padecen los seres humanos conducen siempre a un bien general y, en definitiva, ese mal que se sufre es compensado con la idea de que "todo irá mejor". Sigue Voltaire:

La vieja le dijo a Cunegunda:-Señorita, usted tiene setenta y dos cuarteles en su escudo y ni un centavo; en sus manos está el convertirse en la mujer del señor más grande de la América meridional, que por lo demás tiene un hermoso bigote; ¿va con usted eso de presumir de una fidelidad a toda prueba? Los búlgaros la violaron; un judío y un inquisidor se pelearon sus favores: piense que las desgracias dan ciertos derechos (Voltaire, 1996: 57-58). 
Así que, no importa cuántos males y desgracias se haya sufrido en la vida porque, desde luego, siempre habrá algo o alguien que en un futuro cercano le espere con mejores perspectivas y con la posibilidad de una vida mejor. Además, el ser víctima de tantos avatares le representará tener ciertos derechos. Voltaire relata:

Cerca de la ciudad encontraron a un negro tendido en el suelo, vestido solo a medias, es decir, con un único calzón de tela azul; a ese pobre le faltaban además la pierna izquierda y la mano derecha. - ¡Ay, amigo, por Dios!, le dijo Cándido en holandés, qué haces ahí en el lamentable estado en que te estoy viendo? - Estoy esperando a mi amo el señor Vanderdendur, el famoso negociante, respondió el negro. - ¿Y es el señor Vanderdendur, dijo Cándido, el que te da semejante tratamiento? -Sí señor, dijo el negro, es la costumbre. Nos dan un calzón de tela, como todo vestido, dos veces al año. Si en las azucareras la rueda nos atrapa un dedo, nos cortan la mano; si intentamos huir, nos cortan la pierna; a mí me sucedieron ambas cosas. Ese es el precio al que comen ustedes azúcar en Europa. Cuando mi madre me vendió en la costa de Guinea por diez escudos patacones, me dijo: "Querido hijo, bendice a nuestros fetiches, adóralos siempre, ellos te ayudarán a vivir feliz; tienes el gran honor de ser esclavo de nuestros señores los blancos, y con ello le traerás fortuna a tu padre y a tu madre." Yo no sé si a ellos les traje fortuna, pero ellos a mí no me la trajeron. Los perros, los monos y los loros son mil veces menos desgraciados que nosotros. Cada domingo los fetiches holandeses que me convirtieron me dicen que todos, blancos y negros, somos hijos de Adán. Yo no soy experto en genealogías; pero si todos esos predicadores dicen la verdad, todos somos primos hermanos, y ustedes reconocerán que no es posible tratar de una manera más espantosa a los parientes.

- ¡Oh Pangloss!, exclamó Cándido, apuesto a que no se te ocurrió nunca semejante atrocidad; está visto que finalmente acabaré renunciando a tu optimismo. - ¿Qué es optimismo?, preguntó Cacambo. - ¡Ay!, dijo Cándido, es la pasión por sostener que todo está bien cuando en realidad está mal (Voltaire, 1996: 87-88).

Ante una realidad expectante y cruda, no queda más remedio que disfrazarla con un estúpido optimismo que ayuda a ocultar el sufrimiento de la cotidianidad y la lucha por sobrevivir día tras día, en espera que su desdicha sea recompensada con algún evento especial. Hay más:

Y cuando el par de curiosos se despidieron de Su Excelencia, Cándido le dijo a Martín: -Esta vez estará de acuerdo conmigo en que hemos encontrado al más afortunado de los hombres, pues está por encima de 
todo lo que posee. - ¿No se da cuenta, le dijo Martín, de que está hastiado de todo lo que posee? Hace mucho tiempo dijo Platón que los mejores estómagos no son precisamente aquellos que rechazan los alimentos.

-Pero, dijo Cándido, ¿no hay placer en criticarlo todo, en encontrar defectos allí donde los demás hombres creen ver bellezas? - ¿Es decir, replicó Martín, que hay placer en no tener placer? - ¡Está bien!, dijo Cándido, el único feliz seré yo cuando vuelva a ver a la señorita Cunegunda. -Siempre es bueno tener esperanzas, dijo Martín (Voltaire, 1996: 129-130).

Asimismo, el optimismo recurre a la esperanza como una medida para vencer la soledad de un espíritu abatido por el dolor insoportable de la separación de su amada. Solo queda esperar.

¿Y bien mi querido Pangloss, le preguntó Cándido, luego de haber sido ahorcado, disecado y molidos a palos, y luego de haber sido galeote, todavía sigue pensando que todo sucede de la mejor forma posible? -Sigo fiel a mi primera impresión, respondió Pangloss, pues al fin y al cabo soy filósofo: no me conviene desdecirme, puesto que Leibnitz no ha podido equivocarse, y la armonía preestablecida es la cosa más bella del mundo, de la misma manera que lo sólido y la materia sutil.

Finalmente,

De vez en cuando, Pangloss le decía a Cándido:-Todos los acontecimientos se encadenan en el mejor de los mundos posibles; pues si a usted no lo hubieran echado a patadas de un hermoso castillo por el amor de la señorita Cunegunda, si no lo hubiera agarrado la Inquisición, si no hubiera recorrido América a pie, si no hubiera perdido todos los carneros del gran país de El Dorado, no estaría aquí comiendo pistachos y cidras confitadas. -Tienes razón, respondió Cándido, pero tenemos que cultivar nuestro jardín (Voltaire, 1996: 153).

Queda claro que la búsqueda de un equilibrio y un balance en la vida se da siempre en el devenir de los acontecimientos y de los sucesos, de los eventos y de los accidentes que pueda tener el transitar del hombre por el mundo, que siempre estará buscando compensar sus carencias mediante las múltiples posibilidades que las descargas manifiestan. En consecuencia, la compensación se convierte en una categoría antropológica fundamental, tal como ha sido abordada por autores como Helmut Plesnner y Arnold Gehlen, que han insistido de múltiples maneras en que el ser humano siempre compensa sus carencias naturales mediante descargas. Plesnner, considera que el ser humano quiere salir de la insoportable excentricidad 
de su esencia y busca con ello la compensación de su insuficiencia, de su falta de equilibrio, de su propia desnudez, mediante la cultura; por tanto, lo hace a través la técnica, la expresividad y la transcendencia. La antropología contemporánea determina al ser humano como un ser con defectos que solo puede existir mediante compensaciones; por esto, en el mundo moderno han surgido nuevas formas de compensación que atienden a las diferentes situaciones humanas gestadas históricamente.

Desde las consideraciones previas, las sociedades reclaman la falta o carencia de sentido, añoran aquellos tiempos en que los seres humanos eran capaces de amar, de esperar y de creer con confianza en la realidad, lo cual ya no es posible en el presente. Esta pérdida de sentido es muy propia de la modernidad, se hace dolorosamente perceptible e inteligible y, además, viene marcada por el nihilismo. Así están las cosas en nuestros días en relación con el sentido; el lamento enfático de la falta de sentido se manifiesta, adicionalmente, en algunos fenómenos llamativos como los movimientos de protesta que casi siempre se encuentran articulados políticamente, los movimientos de religiones que buscan su sentido en el fundamentalismo, el retorno a las viejas tradiciones y vanguardias, la expansión sintomática de la producción, del negocio y del capitalismo y, por tanto, del suministro de sentido, que se encuentran a cargo de los consejeros, asesores y terapeutas, los grandes torneos filosóficos sobre el monopolio en la administración del sentido o, en definitiva, la irrupción del sentido incluso en las filas de expertos tecnológicos.

Por estas razones, el sentido deviene deseable en esta época marcada por el consumo, el descontrol y la ostentación de la vida moderna. Como se ha perdido el sentido de la vida, el ser humano busca refugio en sucedáneos; piensa solo en cómo aprovechar las oportunidades y la disposición de medios adecuados para atender a las pretensiones cada vez más desmedidas de las formas modernas de vida. En la moderna sociedad del bienestar, la falta de sentido se evidencia en el intento objetivamente vano de suplir su ausencia con el lujo y la ostentación. Asimismo, el lugar del sentido es ocupado por la distracción, el entretenimiento, el dinero, el éxito, el prestigio, el crecimiento, el fitness, la técnica y la economía. La vida que vive el hombre contemporáneo es una vida vacía, tanto que se precisa dos veces de ella: se necesita un segundo teléfono, un segundo o más televisores, un segundo auto, un segundo cónyuge, una segunda vivienda, una segunda carrera, y todo lo que al hombre se le ocurra. Parece que estas ansias de duplicación 
reconocieran que lo que se vive una sola vez ya no tiene sentido, por lo que se precisa de una compensación consistente en tener que vivirlo dos veces y, en esta forma, tales pretensiones se desbordan por completo.

Sin embargo, se puede pensar que en una sociedad de pretensiones desmedidas no solo sucede que los anhelos compensen la falta de sentido; antes bien, podría ser que el déficit de sentido surgiera mediante la excesiva pretensión de sentido. En otras palabras, cuando divergen la expectativa y el cumplimiento, como en las experiencias de la carencia, jamás existe solo una posibilidad de explicación: o hay poco cumplimiento o, por el contrario, hay demasiada expectativa. Siempre se quiere algo más, y se accede al sentido únicamente a través de las mediaciones, al vínculo y a la relación que tenemos con el mundo (Cfr. Marquard, 1986: 60). De ahí que los seres humanos no desesperen mientras tengan algo que hacer de manera inmediata: el desayuno en las mañanas, planear la agenda del día, solicitar una beca, terminar los estudios de doctorado y todas las tareas diarias que lo retienen y lo hacen llegar tarde a su cita con el no absoluto. No hay suficiente tiempo.

Desde la perspectiva de Maquard, la aceleración del ritmo de la vida diaria y del cambio del tiempo se convierte en un deber histórico. La turbulencia del presente permite recurrir necesariamente a una trascendencia temporal, a un pasado que ya era el camino hacia el único futuro correcto. La turbulencia actual y las confusiones de dirección tienen que ser entendidas como parte de una historia larga y común a todos para que sean soportarlas y poder salvar así la confianza de que uno mismo se encuentra anclado a un momento histórico, en el lugar correcto. Por consiguiente, se puede afirmar que los seres humanos no tienen suficiente tiempo para inventar continuamente todo de nuevo, sino que siempre se recurre a lo que ya es y ya está en vigor. La aceleración del ritmo de la vida precipita el encuentro con la finitud del hombre, con la muerte.

Como bien lo ha sostenido Jankélévitch, el nacimiento no solo condena al hombre a una libertad condicionada, sino a una muerte segura, aunque no se conozca el cuándo, el cómo y de qué del deceso final. La muerte deja de ser un simple tema de traducción del latín o un tema de disertaciones filosóficas, para convertirse en un tema personal (Cfr. Jankélévitch, 2002: 31). Cabe decir, la muerte se convierte en algo serio cuando se toma conciencia del hecho de que esta no es únicamente una desgracia que les ocurre a los otros, o a mí mismo, por lo menos no en un tiempo cercano. A pesar de todo, la muerte no es una eventualidad lejana en el espacio y en tiempo, ya que un 
buen día se descubre que el misterioso problema que se figuraba abarcar también comprende a todos los seres humanos; un buen día al sentir el sonido y los cánticos fúnebres, se comprende de pronto que lo mismo que hoy suena para el vecino, sonará también para nosotros (Cfr. Jankélévitch, 2002: 31). Todo el mundo cede el turno al vecino, el hombre no quiere darse cuenta de que es una realidad impostergable.

En primera persona, la muerte es un misterio que me concierne íntimamente e íntegramente, es decir, en mi nada me pego a ella estrechamente sin poder guardar las distancias con respecto al problema. Se trata de mí, es a mí a quien la muerte llama personalmente por mi nombre, a mí a quien señala con el dedo y de quien tira de la manga, sin darme la oportunidad de hacer pasar delante al vecino; no me queda escapatoria, se me han agotado los plazos; el aplazamiento para más tarde, lo mismo que las coartadas y las postergaciones ahora son imposibles por más empeño que ponga el hombre concernido (Jankélévitch, 2002: 35).

Se diría, por lo anterior, que en el transcurso de la vida hay una especie de finalidad protectora que impide que el hombre piense en su propia muerte. Todo parece estar en el futuro de nuestras vidas; la preocupación por el futuro expresa en última instancia el presente por-venir de la muerte, puesto que esta es el supremo porvenir y el futuro de todos los futuros. La inquietud que produce la profundidad secreta traduce en última instancia la presencia ausente e invisible de la muerte, ya que ella es nuestro secreto mejor guardado. De este modo, la angustia del presente se llama futuro; la angustia del día de hoy, mañana y, la angustia de mañana, pasado mañana pero, en definitiva, nuestra mayor angustia se llama: muerte (Cfr. Jankélévitch, 2002: 59).

Sin duda, bastaría con decir que la muerte no es únicamente la nada de nuestro ser somático, de acuerdo con Jankélévitch, sino también el nada, e incluso el nunca-jamás-nada de nuestro todo psicosomático. Con esto está todo dicho. La idea misma de que la muerte es el no-sentido de la vida, la inconsistencia de todo nuestro ser, la precariedad del devenir y la vanidad de todo lo humano en general, esta idea, si bien no hace la existencia más inteligible, le confiere, sin embargo, una tonalidad y una fisonomía muy especial. Aunque parezca mentira, la vida no sería vida sin una cierta dosis de sin sentido, lo que hace, a su vez, que la vida se rodee de una cierta dosis de misterio (Cfr. Jankélévitch, 2002: 96). Por eso, la muerte no es únicamente lo inconcebible, sino también es lo invisible, lo que contradice y nihiliza la vida; es el absurdo, el espectro de lo amorfo cuya amenaza pesa sobre nuestra existencia y de la que el hombre quiere evitar y quitársela de encima. 
El tiempo del hombre es un tiempo limitado al que su finitud presta una organización, una determinación, una sucesión de momentos, de manera que su tiempo se articula en lapsos sucesivos como los periodos encadenados. Bajo la comprensión de Jankélévitch, estos episodios se limitan unos a otros en el tiempo global de la existencia, de tal manera que ese tiempo global, ese tiempo de todos los tiempos, encajonado entre el nacimiento y la muerte, aparece como un episodio en la eternidad de la nada. De hecho, la muerte no es nunca el no-ser del ser total, sino el no-ser de un ser particular, al igual que la muerte no es la nada metaempírica, sino una desaparición singular y local. Por tanto, la muerte puede ser algo accesorio y reductible a las dimensiones de lo anecdótico, un suceso particular y superficial (Cfr. Jankélévitch, 2002: 363). Nadie es indispensable, la individualidad tiende a ser reemplazada. Del mismo modo que el olvido erosiona y suaviza cualquier desgracia, consuela cualquier desolación, reabsorbe cualquier tragedia en la continuación general, así la pena que deja la muerte de alguien acabará inevitablemente por anularse en el seno de la eternidad. La muerte sella nuestro destino, con lo cual, la muerte rechaza la vida mientras que la vida compensa la muerte.

\section{Algunas conclusiones}

LAS CONSIDERACIONES HECHAS acerca de las posibilidades de la compensación permiten afirmar, en primer lugar, que esta se ha convertido en un concepto clave de la reflexión filosófica sobre los procesos de modernización. El desencantamiento moderno de la realidad es compensado mediante la formación del encantamiento supletorio de lo estético $\mathrm{y}$, asimismo, la artificialización del mundo moderno es compensada por el descubrimiento del paisaje intacto y por el desarrollo de una extremada sensibilidad hacia la naturaleza, el medio ambiente y la conciencia ecológica. En segundo lugar, la pérdida moderna de la tradición causada por las objetivaciones y por el ritmo creciente de cambio de la realidad, es compensada mediante la génesis específicamente moderna del sentido histórico, gracias al nacimiento de los museos como cajas artificiales de recuerdos y memoria. Ahora bien, las anteriores consideraciones pueden no ser suficientes para reflexionar sobre uno de los aspectos fundamentales del ser humano: su coexistencia con el grado de compensación que el hombre busca para restablecer su equilibrio; sin embargo, son reflexiones que no dejan de ser pertinentes e indispensables en cualquier otro análisis al respecto. 


\section{Referencias}

Blumenberg, H. (2008). La legitimación de la edad moderna. España: Pretextos.

Blumenberg, H. (2003). Trabajo sobre el mito. Buenos Aires: Paidós.

JankÉLÉvitch, V. (2002). La muerte. Valencia: Pre-textos.

MARquard, O. (2001). Filosofia de la compensación. Estudios sobre antropología filosófica. Barcelona: Paidós.

Marquard, O. (1986). Apología de lo contingente. Valencia: Novatores.

McLuhan, M. (1985). La Galaxia de Gutemberg. España: Planeta.

SLOTERDIJK, P. (2006). Esferas III. Madrid: Siruela.

SLOTERDIJK, P. (2004). Esferas II. Madrid: Siruela.

Voltaire. (1996). Cándido. Bogotá: Norma.

WeinRICH, H. (1999). Leteo. Arte y Crítica del olvido. Madrid: Siruela. 
